Illinois State University

ISU ReD: Research and eData

Theses and Dissertations

$6-25-2018$

\title{
Trauma and the Credibility Economy: An Analysis of Epistemic Violence and its Traumatic Functions
}

Gina Stinnett

Illinois State University, gestinn@ilstu.edu

Follow this and additional works at: https://ir.library.illinoisstate.edu/etd

Part of the Rhetoric Commons, and the Women's Studies Commons

\section{Recommended Citation}

Stinnett, Gina, "Trauma and the Credibility Economy: An Analysis of Epistemic Violence and its Traumatic Functions" (2018). Theses and Dissertations. 922.

https://ir.library.illinoisstate.edu/etd/922

This Thesis is brought to you for free and open access by ISU ReD: Research and eData. It has been accepted for inclusion in Theses and Dissertations by an authorized administrator of ISU ReD: Research and eData. For more information, please contact ISUReD@ilstu.edu. 


\section{TRAUMA AND THE CREDIBILITY ECONOMY: AN ANALYSIS OF EPISTEMIC VIOLENCE AND ITS TRAUMATIC FUNCTIONS}

\section{GINA STINNETT}

\section{Pages}

In this thesis, I argue that the work done in philosophy on epistemic injustice can put pressure on the assumptions driving the work of both trauma theory and rhetorical theory. In addition to arguing how epistemic injustice can reinforce trauma, I argue that epistemic injustice has its own power to traumatize. I refer to this as "epistemic trauma," or a trauma to one's ability to know their experience and to make a claim based on this knowledge. Research on epistemic injustice states that when one encounters repeated epistemic injustice, they become less likely to share their experiences at all—they fall into a coerced self-silencing. In the context of trauma, epistemic injustice can take away one's ability to make sense of their traumatic experience. If they cannot "know" their experience, they cannot speak it. I differentiate among physical trauma, psychological trauma, and epistemic trauma, which I believe all function in different ways - sometimes in the same traumatic experience. If physical trauma is the literal trauma to one's body, and psychological trauma is the damage to one's psyche as a result of this trauma, then epistemic trauma would be the damage to one's sense that they are able to know and make sense of their experiences, and make a claim based on this experience.

KEYWORDS: trauma, rhetoric, narrative, epistemology 


\title{
GINA STINNETT
}

\author{
A Thesis Submitted in Partial \\ Fulfillment of the Requirements \\ for the Degree of \\ MASTER OF SCIENCE \\ Department of English \\ ILLINOIS STATE UNIVERSITY
}

2018 
(C) 2018 Gina Stinnett 
TRAUMA AND THE CREDIBILITY ECONOMY: AN ANALYSIS OF EPISTEMIC VIOLENCE AND ITS TRAUMATIC FUNCTIONS

GINA STINNETT

COMMITTEE MEMBERS:

Amy Robillard, Chair

Alison Bailey 


\section{ACKNOWLEDGMENTS}

It truly took a village to make this thesis possible, and because of that, I have a number of people to thank:

My advisor, Amy, whose guidance has brought me through the most difficult task of my educational career so far, and whose mentorship and support has helped me to accomplish things I never thought were possible,

Alison, whose wisdom informed much of this thesis and who (among several other lessons) continues to teach me the importance of strength and self-care,

Kass, whose support— both academic and emotional—-helped me get to the point of grad school in the first place, and who has seen me through some of the most difficult points of my time here, The students and faculty in the English department and Women's and Gender Studies Program, whose stellar instruction and mentorship make me endlessly proud to be a two-time ISU alum, especially Dr. Joe Amato, Dr. Kyle Ciani, Dr. Angela Haas, Dr. Julie Jung, Dr. Erika Sparby, and the late Dr. Rhonda Nicol, My amazing Master's cohort: Karishma, Becca, Ethan, Andrew, and Brie, My office-mates in WGS: Jamie, Dr. Gerschick, Dr. Diaz-Kozlowski, and Emma, who have overheard me crying about this thesis more times than I'd care to admit, and Becky, my best friend, the God I feel in this Chili's tonight, and the person who has provided endless love and light through this entire journey.

G. S. 


\section{CONTENTS}

Page

ACKNOWLEDGMENTS

CHAPTER I: INTRODUCTION 1

$\begin{array}{ll}\text { Epistemic Injustice } & 2\end{array}$

$\begin{array}{ll}\text { Trauma Studies } & 5\end{array}$

CHAPTER II: WHEN/WHERE/HOW CAN TRAUMA BE SPOKEN? 10

Epistemic Terrains and Traumatic Narratives $\quad 12$

$\begin{array}{ll}\text { Epistemic Terrains in Aftermath } & 15\end{array}$

The Personal is Political, Philosophical, Powerful 23

CHAPTER III: TRAUMA AND MEMORY: FALSE CONSTRUCTIONS, RESURFACED

TRAUMA, AND THE PARADOXES OF TRAUMA 26

$\begin{array}{ll}\text { Trauma and the Construction of Memory } & 27\end{array}$

Traumatic Retellings 35

CHAPTER IV: TOWARDS A THEORY OF EPISTEMIC TRAUMA

Physical Trauma, Psychological Trauma, and Epistemic Trauma 42

An Applied Theory of Epistemic Trauma 45

$\begin{array}{ll}\text { Scenario One } & 45\end{array}$

$\begin{array}{ll}\text { Scenario Two } & 45\end{array}$

$\begin{array}{ll}\text { Scenario Three } & 46\end{array}$

The Annihilated Self of Epistemic Trauma 49

The Paradoxes of Epistemic Trauma $\quad 51$

Further Implications of a Theory of Epistemic Trauma 52 
WORKS CITED 


\section{CHAPTER I: INTRODUCTION}

As Judith Herman states in Trauma and Recovery: The Aftermath of Violence-From Domestic Abuse to Political Terror (1992), sharing one's trauma is an integral part of recovery. In fact, Herman argues that "recovery begins when truth is recognized" (1, emphasis mine). However, the privilege to speak one's trauma and have it recognized to be true is not distributed evenly along identity lines. In many cases, an audience can fail to hear a speaker's testimony because of their own assumptions about the speaker's credibility. This is especially true with regards to testimonies about trauma. Because of the way that trauma tends to be spokenerratically, out of order, either overly emotional or void of emotion-survivors' experiences are heavily scrutinized. This scrutinizing is compounded when one's identity works against their credibility. Epistemic injustice (when one is not believed for prejudicial reasons) has particularly devastating effects in the context of trauma narratives. If recovery can begin only when one gives voice to their trauma and, in turn, has it recognized to be true, then how might epistemic injustice affect one's chances to recover from their trauma? When we as audiences deny others the right to be heard, are we also denying the right to recovery? Scholars of trauma have addressed the importance of telling one's story (Herman; van der Kolk; Caruth), discussed the value of writing one's story (Hamilton; Worsham), however, if one's identity puts them at a disadvantage for sharing their experience and having it accepted as true, what groups are given access to this important first step of healing from trauma?

In this thesis, I argue that the work done in philosophy on epistemic injustice can put pressure on the assumptions driving the work of both trauma theory and rhetorical theory. In addition to arguing how epistemic injustice can reinforce trauma, I argue that epistemic injustice has its own power to traumatize. I refer to this as "epistemic trauma," or a trauma to one's ability 
to know their experience and to make a claim based on this knowledge. Research on epistemic injustice states that when one encounters repeated epistemic injustice, they become less likely to share their experiences at all — they fall into a coerced self-silencing. In the context of trauma, epistemic injustice can take away one's ability to make sense of their traumatic experience. If they cannot "know" their experience, they cannot speak it. I differentiate among physical trauma, psychological trauma, and epistemic trauma, which I believe all function in different wayssometimes in the same traumatic experience. If physical trauma is the literal trauma to one's body, and psychological trauma is the damage to one's psyche as a result of this trauma, then epistemic trauma would be the damage to one as a knower - a damage to their sense that they are able to know and make sense of their experiences, and make a claim based on this experience.

\section{Epistemic Injustice}

In her book Epistemic Injustice: Power and the Ethics of Knowing, Miranda Fricker explores a concept she calls epistemic injustice. Fricker argues that epistemic injustice works in two forms - testimonial injustice and hermeneutical injustice. She defines testimonial injustice as “when prejudice causes a hearer to give a deflated sense of credibility to a speaker's word" (1). When testimonial injustice is committed, it is because a prejudice against the speaker's identity makes them a "less credible" speaker in the eyes of the hearer, which silences the speaker's narrative. This functions in many ways. For example, we give less credibility to women's testimonies because of the common prejudice we have of women as not reliable knowers. Fricker's example from the film adaptation of The Talented Mr. Ripley illustrates how the common stereotype of women as clueless can function as testimonial injustice. In this example, a male character, Herbert Greenleaf, silences a female character, Marge Sherwood, by stating that "there is female intuition, and then there are facts" (9). Because of his prejudice that women are 
irrational, he cannot hear Marge's testimony. In cases of testimonial injustice, the speaker, by the very nature of his or her identity, loses the credibility they would have had otherwise. Fricker also explores a concept called "hermeneutical injustice," which she defines as "the injustice of having some significant area of one's social experience obscured from collective understanding owning to a structural identity prejudice in the collective hermeneutic resource" (2).

Hermeneutical injustice takes place when collective interpretive resources render certain experiences unintelligible. Fricker illustrates this with her example of sexual harassment. Before Lin Farley coined the term in 1975, there were no shared resources that accurately described the experiences that so many women have had in the workspace, at school, on the street, or basically just in the entire world. The "collective interpretive resources" gave people no way of processing what sexual harassment actually was_-people would think "he just likes me," or "he's just being annoying." The hermeneutical injustice lay in the fact that women could not make sense of this experience, because the dominant narrative did not provide the resources to label this treatment as a problem.

In her 2011 piece "Tracking Epistemic Violence, Tracking Practices of Silencing," Kristie Dotson expands upon and challenges Fricker's definition of epistemic injustice through her use of the term epistemic violence, originally coined by Gayatri Spivak who defined the term as "actively distorting and obstructing knowledge." The use of violence as opposed to oppression allows this term to account more for the harms of silencing - epistemic violence does not result in just a failed communicative exchange, but a "disappearing of knowledge" in favor of "alternative, often Western, epistemic practices" (1). In labeling this as epistemic violence, Dotson makes the assertion that the silencing of stories is in and of itself an act of violence. Dotson defines epistemic violence as a "failure, owing to pernicious ignorance, of hearers to 
meet the vulnerabilities of speakers in linguistic exchanges" (239). Dotson argues that in order for a communicative exchange to be successful, there needs to be reciprocity between the speaker and the audience. Essentially, the speaker and the audience need to "meet each other halfway" - the speaker must share a testimony, and the audience must be willing and able to hear it as truth. According to Dotson, epistemic violence occurs when the audience fails to "meet the speaker halfway" (239). This explanation makes it clear that the responsibility for epistemic violence falls on the shoulders of the audience - the speaker can only do so much to meet the audience, and when the audience automatically assumes that the speaker is not a credible source of knowledge based on their identity, they fail to do their "part" in the communicative exchange. Dotson presents two social practices of silencing: testimonial quieting and testimonial smothering. Both of these forms arise from different instances in which an audience fails to "meet the speaker halfway." In the case of testimonial quieting, the audience's failure is through their inability to "identify a speaker as a knower" (242). To illustrate this concept, Dotson uses the example of how black women are less likely to be seen as competent. In this situation, the audience's "pernicious ignorance" arises from the ubiquitous narratives of black women as either “mammies, matriarchs, welfare mothers, and/or whores." Because the audience cannot see past these "controlling images," they cannot see black women as "knowers," and therefore cannot offer the reciprocity between audience and speaker that is necessary in a communicative exchange - the testimony ends up falling flat, as if it were never shared at all.

Testimonial smothering, on the other hand, refers to "the truncating of one's own testimony in order to insure that the testimony contains only content for which one's audience demonstrates testimonial competence" (244). This happens when the testimony is controversial, complex, or just difficult for the audience to hear-the audience will fail to really "hear" it 
because of their lack of understanding. In truncating their testimony, a speaker is working to make their testimony intelligible for specific audiences that would otherwise not be able to "hear" the testimony. Marginalized groups that experience repeated acts of silencing will anticipate this silencing, and by attempting to make their testimonies more intelligible, they can work to avoid the harms of silencing. For example, a woman who is repeatedly told that she was at fault for being raped eventually might change the way she tells her story to appeal to the fact that she "did everything right." Or, a person of color who is used to not being believed when they share a testimony of police brutality might opt to not share their testimony at all. Even though this is a "self-silencing" of the speaker, the culpability for this silencing is still on the audience. This is because the silencing only occurs because of the audience's lack of ability to understand a speaker's testimony — it is a "coerced silence" (244).

\section{Trauma Studies}

Many trauma theorists have discussed the importance of speaking one's trauma. In her book Trauma and Recovery: The Aftermath of Violence -From Domestic Abuse to Political Terror, Judith Herman articulates how "reconstructing the story" functions as an important step in the recovery process. According to Herman, "reconstructing the story" takes place in the second stage of recovery and works to "transform the traumatic memory so that it can be integrated into the survivor's life story" (Herman 175). Through reconstructing their trauma, Herman states that survivors can undertake in a "systemic review of the meaning of the event" (178). When survivors are able to articulate a "story" of the traumatic event they experienced, they can begin to take more ownership over the event and start to regain a sense of control. However, as Herman articulates, a story can only be successfully reconstructed after the survivor has established safety. She stresses that this stage can only commence once the survivor has 
established a working relationship with their therapist, and feels safe working through this reconstruction with them.

Of course, there are many instances in which the retelling of a traumatic event either does not or cannot take place in a "safe" setting. Oftentimes, trauma survivors wish to retell their trauma to friends or family in hopes that the act itself will help them "heal" from the trauma. While this usually does not take place in a physically unsafe environment, it can certainly take place in an emotionally unsafe environment. Since the listener in this situation is not a trained therapist, they often do not know how to properly "witness" trauma. This can not only lead to issues for the listener, as articulated by Dori Laub in "Bearing Witness or the Vicissitudes of Listening," but can have disastrous effects for the speaker. A study conducted by Lindsay M. Orchowski, Amy S. Untied, and Christine A. Gidycz found that the response one receives when they disclose an incident of sexual or dating violence is often the top determiner of whether or not they will develop Post-Traumatic Stress Disorder (PTSD). They argue that one of the most common risk factors in this context is when listeners refuse to acknowledge truth in a trauma survivor's testimony. If, as Herman states in Trauma and Recovery, "recovery begins when truth is recognized," epistemic injustice can not only stunt recovery, but actually act as the catalyst for one's PTSD.

Another important facet of trauma theory is the articulation of the ways in which trauma is spoken. According to Herman, "people who have survived atrocities often tell their stories in a highly emotional, contradictory, and fragmented manner which undermines their credibility and thereby serves the twin imperatives of truth-telling and secrecy" (1). Dori Laub illustrates this in "Bearing Witness"- when the Holocaust survivor attempted to testify to her experience in Auschwitz, she incorrectly remembered the number of chimneys that blew up. Because of this, 
many of the historians in attendance ended up writing off her entire testimony because of this inaccuracy. However, this type of small inaccuracy is one of the hallmarks of testifying about trauma - the way survivors of trauma remember their traumatic events becomes jumbled. Because of the very nature of how trauma works in the brain, trauma survivors' testimonies end up being seen as inherently incapable of being credible.

The work done in philosophy on epistemic injustice explores the ways in which identity can affect one's ability to speak and be heard. Likewise, the research on credibility done in rhetorical studies explores the many ways in which speakers can make themselves more credible. By putting these fields in conversation with one another, my thesis will reveal the ways in which they are inexorably linked. We commonly think of a "credible" speaker as one who "has their story straight," can provide extrinsic evidence to support their testimony, and can attest to a "good moral character." These are all commonly absent in the context of trauma testimoniesthe nature of how trauma is spoken is often not a "straight story," there is often little to no "evidence" to support that one's trauma was "real," and more often than not, victims of trauma are blamed for either causing the trauma, or not doing enough to stop it. A knowledge of epistemic injustice and trauma - and more specifically, the ways in which they work togetherwill complicate these notions that rhetoricians have of what makes a speaker credible. Drawing on these concepts, my thesis explores what it means to be a "credible" speaker in the context of a society that unevenly distributes credibility based on one's identity. How does identity prejudice lock people out from ever being seen as credible? How can this practice turn people into "traumatized knowers?" In order to explore the links between trauma, epistemic injustice, and rhetorical studies, I rhetorically analyze two memoirs that center around trauma: Susan Brison's Aftermath: Violence and the Remaking of a Self and Rahna Reiko Rizzuto's 
Hiroshima in the Morning. In doing so, I explore how epistemic injustice functions both within the texts and in the response to the texts. These texts I have selected offer numerous accounts of how the narrator was unable to share their traumatic experience and be "heard," whether it was because of their identity, because of how the trauma allowed itself to be "spoken," or because of others' misconceptions of how trauma functions.

In my second chapter, I focus on epistemic injustice in Aftermath. I explore how epistemic injustice functions both within the text and in the response to the text, using Fricker and Dotson's terminology to rhetorically analyze how Brison's identity as a traumatized self affected her credibility, with a special focus on how Brison's own hermeneutical framework (analytical philosophy) did not allow for her to make sense of her own experience. In order to speak about her sexual assault, she needed to seek out a hermeneutical environment in which this type of experience can be heard.

In my third chapter, I focus on Rizzuto's Hiroshima in the Morning, and how this same dilemma of hermeneutical framework applied to the Hiroshima survivors' testimonies of the bombing. Why was it that the survivors were unable to speak about their experiences until after 9/11? What was it about a post 9/11 discourse that allowed for more understanding of Hiroshima survivors' accounts that was impossible in the aftermath of Hiroshima? Through Fricker and Dotson's frameworks, I explore the ways in which a global context that focused on such aftermaths helped to give Hiroshima survivors a platform in which their trauma was intelligible to a Western audience.

In my fourth chapter, I theorize what I believe is a result of epistemic injustice that has not yet been discussed - epistemic trauma, or a trauma to one's ability to know their experience and make a claim based on this knowledge. How does epistemic injustice further traumatize 
someone who has been through a traumatic experience? What does it mean to be a "traumatized knower," and how does epistemic injustice create them? How can we combat both epistemic injustice and epistemic trauma?

Finally, in my conclusion, I explore possible implications of this work and raise questions for further investigation — what are the broader implications of epistemic injustice and epistemic trauma in a cultural context that posits that we should simply "believe all survivors?" How can we find a balance between correcting our epistemic injustices while also recognizing the harm that can be done by people who legitimately make false claims of a traumatic experience? How does epistemic injustice stunt the possibilities for writing about trauma, and how do theory and creative writing inform one another? In what ways is writing one's experience resistance against epistemic injustice, and how can we encourage this form of resistance? 


\section{CHAPTER II: WHEN/WHERE/HOW CAN TRAUMA BE SPOKEN?}

In her 2003 memoir Aftermath: Violence and the Remaking of a Self, Susan Brison recounts her experience with sexual assault and attempted murder, and the ways in which this assault and its aftermath forced her to essentially rebuild not only herself, but her frameworks for making sense of the world around her. Brison found that, when it came to discussing her trauma, her home field of analytic philosophy offered her no resources for making sense of her experience - it simply was not intelligible under these frameworks. What had previously been her primary means of understanding the world around her was no longer a tool she could use in order to make sense of her experience. Because of the assumptions of analytic philosophy, her experience could neither be spoken nor heard under that framework—what is valued as a truthful narrative in the field of analytic philosophy is at odds with how trauma narratives tend to be spoken. However, just because her experience was unable to be spoken in this particular space did not mean that there would be no space whatsoever where her experience could be intelligible - the field of feminist philosophy in particular would prove itself capable of embracing Brison's narrative. Epistemic injustice is not simply a phenomenon that takes shape in the same way across all spaces. In fact, subjugated groups regularly carve out counter-spaces in which their stories can be given uptake. Brison found her counter-space in feminist philosophy, which not only makes room for but embraces the power of the personal narrative. In this space, Brison was able to use her personal experience as a tool for analysis and as a site of knowledge. Because of this ability, she was able to heal in a way that would not have been possible had she not sought out this counter-space.

In “The Unlevel Knowing Field: An Engagement with Dotson’s Third-Order Epistemic Oppression," Alison Bailey explores the phenomenon of epistemic terrains influencing their 
inhabitants through her concept of the "unlevel knowing field." Bailey uses this term to discuss the ways in which "epistemic cartographies are politically saturated," and how because of the "home turf advantage" given to socially dominant groups, "members of marginalized groups must learn to navigate this field creatively" (Bailey 2014). In our "epistemic cartography," there are certain spaces in which the testimonies of marginalized groups are unintelligible, and certain spaces in which the members of the space possess the frameworks necessary to hear the testimony. In our current epistemic context, members of marginalized groups must seek out these spaces in order to share their experiences-for example, one's experience with police brutality is generally not given uptake in our wider cultural context, but such testimonies can be fully heard in the context of a Black Lives Matter or Black Student Union meeting. These spaces are ones of healing, not only because they are a retreat from the usual epistemic injustice faced by marginalized groups in larger contexts, but because they allow marginalized groups to finally speak and be heard. By seeking out these counter-spaces in our "unlevel knowing field," we can begin to resist the phenomenon of epistemic injustice.

In this chapter, I engage with Brison's memoir through Bailey's lens of the "unlevel knowing field" to explore the ways in which the retelling of a traumatic experience necessitates seeking out these counter-spaces where trauma is actually intelligible, and using these spaces to counteract future silencing. I draw on Brison's experience with how analytic philosophy "failed" her in the aftermath of her sexual assault and how feminist philosophy filled this gap for her to analyze the ways in which the collective hermeneutical resources of certain spaces are indicators of how likely it is for a testimony of trauma to receive uptake. Finally, I engage with Brison's account of why the personal narrative is important, not only as an act of healing, but as an act that carries immense political power when shared in the "right" space. 


\section{Epistemic Terrains and Traumatic Narratives}

When it comes to the sharing of a traumatic experience, many people think that the most important consideration is who one shares with. This idea has a certain amount of truth to it - it is important for those who are recovering from a traumatic experience to be able to share their story with people who are empathetic listeners and who care about the person sharing their story. Something we think less about in terms of sharing a traumatic experience is the context in which we are sharing it. When it comes to speaking trauma, the "audience analysis" that is so often spoken of in rhetorical theory is not necessarily the best indicator of whether or not a trauma narrative will receive uptake. A person can have all the hallmarks of being the "right" person to share a traumatic experience with — they are someone you trust, they are committed to social justice, and a generally empathetic listener - but if the exchange is not taking place in the most efficient "hermeneutical playing field," this exchange can still fall flat. Under frameworks that distort our ideas of what trauma is and how it is narrated, even the most empathetic of listeners can fall victim to false perceptions of a traumatized speaker. This is because of the social nature of epistemic injustice - it does not occur because of an individual hostile listener, but because of the social influences our spaces have on potential listeners. The narrative of trauma will simply not be intelligible within a rhetorical context that does not take the nature of trauma into account. When this is the issue, the solution is not to find another, "better" listener - it is to either seek out or carve out a space that fosters an audience's ability to bear witness to another's traumatic experience. Listeners and the spaces in which they exist influence each other in ways that we do not always anticipate - if we see people as purely individual and not a product of the epistemic terrains they exist in, we lose sight of this fact. Epistemic injustice occurs because of an identity 
prejudice, and this prejudice is not a result of an individual choice - it is shaped by the individual's space.

So, what constitutes a space that would properly foster a retelling of a traumatic experience? The most important factor is that it must be a space in which trauma is intelligible. The rhetoric (or, rather, a-rhetoricity) of trauma makes it difficult for this to always be possible. Trauma is "spoken" in a manner that defies our conceptions of how an experience "should" be told if it is to be perceived as truthful. It is messy, emotional, and does not follow any sort of linear structure. Because of this, people's traumatic experiences are often seen as untrustworthy right from the start. This means that for a space to be one in which a traumatic experience can be shared, its inhabitants must have a working knowledge of trauma and how it manifests itself in a survivor's narrative. When people within a space understand the ways in which a traumatic narrative is told, they are at much less of a risk for finding these narratives unintelligible. Our general cultural understanding of trauma comes from extremely simplified representations of what it means to be traumatized. Many people think of PTSD as something that only affects combat veterans, and that even then, the symptoms are not as "disruptive" as they actually tend to be. When one looks at how trauma and PTSD are represented in popular media, it is easy to see why this is the case. We are constantly bombarded with media images of people who are "beautifully broken" by their trauma, whose PTSD symptoms are never too intense for the general public to handle, and who can find some sort of "higher meaning" in their traumatic experience. The research done by trauma theorists, of course, refutes this representation of trauma, but this research often does not reach as many people as the "feel-good" narratives. People who do not specifically seek out trauma research only have popular representations of trauma as a reference point. The real experiences of traumatized people are not as easily 
sensationalized or packaged into an easily digestible narrative, so they are simply pushed to the side in favor of the "easier" narratives. As a culture, we become addicted to this "feel-good" version of traumatic stories. We want to believe that someone can go through a horrific experience, but come out of it as the "new and improved" version of themselves who is barely distinguishable from their "pre-traumatized" self. Our culture of positivity craves this narrativeit is easy to understand and it puts us at ease. When we believe that trauma only happens to a small percentage of our population and that when it does happen, its symptoms are as nonintrusive as possible, we are able to convince ourselves that trauma is something that cannot affect our lives. We are able to separate ourselves completely from the devastating realities of trauma. Even though it can shield us emotionally, this misunderstanding of how trauma works puts us at a huge disadvantage for successfully witnessing trauma when we encounter it in real life. If our entire means for interpreting trauma comes from these misrepresentations of trauma, we will never be able to deal with the full range of traumatic experiences - they will forever be unintelligible. Our urge to immediately discredit the more "erratic" and "emotional" trauma narratives is born out of this distortion of how trauma works. When we cultivate spaces that combat this false representation, we pave the way for trauma narratives to be shared and actually received.

A space that gives uptake to trauma survivors' experiences also needs to be comprised of people who are actually ready to take on these traumatic narratives. While it is true that the norms of spaces have a heavy influence on those who inhabit them, this influence exists in conjunction with those who inhabit it - the phenomenon of a failed listening does not occur wholly on either end, but as a result of factors on both sides. Witnessing trauma is extremely difficult work - if one is not "ready to receive" (Felman) a traumatic experience, it is impossible 
for that person to engage in a way that is productive for both the speaker and the listener. In "Bearing Witness, or the Vicissitudes of Listening," Dori Laub articulates the many ways in which bearing witness to someone else's traumatic experience-even through just a retelling of the experience - can leave the listener with symptoms of secondary trauma if they are not prepared to take on the task of bearing witness. An unexpected traumatic story leaves the listener with no room to process, much like the traumatic event itself left the survivor with no room to process. Because of this, the speaker is almost automatically subjected to the negative effects of a failed retelling of a traumatic story. How can one be expected to be a supportive witness to someone else's trauma if they, too, are experiencing trauma symptoms from not being prepared for the retelling? It is beneficial to both the speaker and the listener when the listener is prepared and willing to take on the work of bearing witness to trauma.

Spaces in which these conditions are met are not a fantasy-in fact, members of marginalized groups have been carving out these types of spaces for decades. However, for the purpose of this chapter, I focus specifically on the "space" of feminist philosophical theory-the space in which Brison's narrative could be both spoken and received. Within a field like feminist philosophy, the sharing of trauma narratives can function as not only an act of healing for the speaker, but as an act of creating knowledge. When we enter spaces that give epistemic weight to personal narratives, especially traumatic narratives, we are more equipped to resist epistemic injustice.

\section{Epistemic Terrains in Aftermath}

In Aftermath, Brison describes her experience with discovering the affordances and limitations of two different fields — analytic philosophy and feminist philosophy. Brison's home field is analytic philosophy, and is understandably what she relied upon for most of her life to 
make sense of the world around her. However, Brison found that the tools of analytic philosophy were not helpful to her in making sense of what happened to her. When she tried to write about her assault based on what she had always known, she found that "all [she] could come up with was a list of paradoxes" (1). On top of her own personal crisis, she found herself continuously encountering people who simply could not understand trauma, and instead of being the "empathetic listener" she was looking for, urged her to "move on" and "forget." Because of her inability to share her experience under these frameworks, Brison had to seek out a space that would foster listeners and discourses that would be able to receive her traumatic narrative.

Brison's experience mirrors that which Bailey describes in "The Unlevel Knowing Field." The reason Brison's experience with sexual assault could not receive any uptake was the result of the "epistemic terrain" being ill-equipped to handle such a narrative. Analytic philosophy is a field that focuses on the clarity, precision, and logical reasoning of arguments. There is a heavy emphasis on empirical evidence, and because of this, personal narratives are generally not accepted as arguments in the field. This rigid adherence to only the most purely empirical evidence is so infamous that there is even an internet meme, "Scumbag Analytic Philosopher," that jokes about some of the issues people take with the culture within the field. The epistemic terrain within analytic philosophy is clearly cemented — there is no room for the personal, and therefore any personal narrative is going to be unintelligible. This rejection of the personal is compounded when it comes to traumatic narratives. Trauma narratives are inherently emotional. They are more often than not messy, illogical, and unclear. Empirical evidence is not guaranteed to exist when it comes to trauma; in fact, in the case of sexual assault, there is often no "evidence" at all. There is often little precision or linearity when it comes to a traumatic narrative, especially since traumatic events are often written into the psyche in a way that lacks 
either. There is simply the attempt to narrate the un-narratable, leading to the "paradoxes" that Brison describes. This leaves a trauma narrative inherently at-odds with a field like analytic philosophy. Any space that privileges objective rationality will not be able to "receive" someone's traumatic experience. Under such a framework, a trauma narrative would never function as an acceptable truth-claim.

This is, of course, not a phenomenon exclusive to the field of analytic philosophy. The ways in which trauma is spoken leave it unintelligible in many spaces. In a way, it is almost easy to commit epistemic injustice against trauma narratives because everything about them goes against what we see as a "credible" narrative. Epistemic injustice is a problem that is larger than just individual people's own prejudices clouding their credibility judgment- - the problem starts at the level of the epistemic terrains we operate on. It is the epistemic terrain that not only produces and nurtures the stereotypes individuals fall victim to, but leaves counter-narratives as unintelligible and therefore, untruthful. What makes Brison's experience unique is that her struggles with the "unlevel knowing field" were not only with other people finding her experience to be unintelligible, but with her own mode of reasoning being "of no use in making [her] feel at home in the world" (preface). For Brison to be able to share her experience, and in turn, heal from the experience, she needed to seek out an epistemic community in which she would not fall victim to the unintelligibility of trauma. One cannot divorce a trauma narrative from the very elements that leave it unintelligible under frameworks like those of analytic philosophy, so rather than continue to attempt to make sense of these experiences under frameworks that leave no room to do so, we need to find the communities that honor the hallmarks of trauma narratives as important meaning-making practices. 
This is where the field of feminist philosophy comes in. The epistemic terrain of feminist philosophy is one that almost perfectly exemplifies the necessary conditions of a space in which one can share traumatic experiences. As Brison herself describes, feminist philosophy is not averse to the personal as analytic philosophy is. Rather, the field of feminist philosophy embraces the knowledge that that is created from sharing personal narratives. This knowledge is not only valued in feminist philosophy, it is essential. Brison cites the "intellectual necessity" of writing in the personal, which not only "exposes previously hidden biases in the discipline's subject matter and methodology," but more importantly, "facilitates understanding of (or empathy with) those different from ourselves" (26). As a field, feminist philosophy works to challenge the assumptions of "classic" Western philosophy, and a major part of this is recognizing that there is value in one's experience. How would one theorize about sexist oppression without sharing their own experiences with it? When we push against the binary between the personal and the theoretical, we allow ourselves to not only hear the personal narrative, but learn from it.

Feminist philosophy also values the knowledge inherent in emotions in a way that analytic philosophy tends not to. Emotions, especially anger, are seen as "a tool to declare agency" (Frye). Rather than view emotions as a reason to discredit one's testimony, feminist philosophy sees them as integral parts of sharing one's experience- the emotions themselves are testimony to the injustices that the speaker has experienced. In the case of trauma, the emotions inherent to a traumatic narrative are seen as markers of the effect that trauma has had on the speaker. This is not to say that feminist philosophy does not value rational thought like analytic philosophy does - the field simply has a different definition of what can be considered rational. The anger or sadness expressed by a survivor of trauma is seen as rational in and of itself. If 
these emotions are seen evidence of injustice, then it would rationally follow that when one suffers an injustice, they will be angry or sad. In turn, these emotions will come out when they are sharing their traumatic experience. When emotions are not seen as some sort of automatic credibility penalty, trauma survivors can share their experiences and have them heard much more easily.

Brison's own narration within her memoir shows the role that her retellings had in her recovery from trauma. Brison describes first feeling afraid of other people knowing that she had been sexually assaulted and nearly killed — she feared that her "professional work would be discredited, that [she] would be viewed as biased, or, even worse, not properly philosophical" (19). To Brison, the narrative itself would be her undoing - it would somehow make her "not philosophical." In the same line, Brison describes her eventual shift towards being more afraid not to tell her story - in embracing feminist philosophy's emphasis on the personal as an important theoretical and political tool, she was able to not only use her narrative for her own recovery, but as an impetus for further activism around issues of sexual violence. Her memoir is an act of silence-breaking. When both the traumatic event itself and its aftermath are silencing, narrating the event is a direct push back against the very silence that causes epistemic violence. Her memoir is her whole experience as she wants to share it, without the testimonial smothering facilitated by the police she reported her assault to. Instead of truncating her testimony in order to appeal to a group of listeners who would otherwise rush to blame her, she could tell her story as she actually experienced it. The version of her experienced she shared with the courts was a defense against silencing; her memoir is in defiance of it. The structure of Brison's memoir also shows her embracing of her narrative as a piece of knowledge. Throughout her memoir, the personal and the philosophical are intertwined, never separate - in doing so, Brison asserts her 
experience as knowledge-bearing, and inherently philosophical. When Brison was no longer afraid of what a retelling would mean for her, she was able to exercise more agency over her story, especially when others in her life wanted to "pretend it didn't happen" (13). For Brison, her memoir is an act in asserting knowledge and power, recovering through narrativizing her experience, and acceptance of the details that are still "nonsensical" to her-as Brison herself states, "there was never a coherent self (or story) there to begin with" (115). While feminist philosophy and trauma theory could help Brison share her story in the sense that it allowed her to realize that her voice and experience had value and carried knowledge, it also helped her to realize that certain elements of her experience would always be "nonsensical"- and that this was okay.

When Brison allowed herself to theorize in the personal voice (working out of a feminist philosophical framework), she found that she was actually able to write about her experience in a way that helped her cope with what her trauma had done to her. Brison writes about how a traumatic event becomes what she calls a "selfannihilation" (38). She describes this as an "undoing of the self" that occurs when a trauma "not only shatters one's fundamental assumptions of the world, but severs the sustaining connection between the self and the rest of humanity" (40). Brison quotes Judith Herman in saying that "the traumatic event thus destroys the belief that one can be oneself in relation to others," and brings Herman's theorizing further to argue that after a trauma, "one can no longer be oneself to oneself, since the self exists fundamentally in relation to others" (40). This is what results in survivors of trauma often mentioning that they are "not the same person" as they were before their traumatic event, or even more explicitly stating that the person they once were "died" during the event. In the words of one survivor of a Nazi death camp, "one can be alive after Sobibor without surviving Sobibor" 
(38). The "bodily continuity ... continuity of memory, character traits, or other psychological characteristics that makes someone the same person over time" (40) are often all disrupted by a traumatic event. The body is often the site of a traumatic event, meaning that one's bodily continuity is literally altered through physical scars and injuries to the body. Even after the physical scars fade on the body, the body can serve as a reminder of the event, or, as Brison describes, become a perceived "enemy." Memory is also fractured by a traumatic event— survivors of trauma often remember the event in fragments, out of order, or not at all. Also, if a survivor experiences dissociative symptoms of PTSD, their memory even long after a traumatic event can be something that is not necessarily guaranteed. Character traits and psychological characteristics are also majorly altered after a traumatic event. Psychological traits often take the larger hit, as the symptoms of PTSD can wreak havoc on one's sense of mental health and stability—the hypervigilance, depression, and sleep disorders that exist in conjunction with PTSD can alter one's psychological traits past the point of recognition for the survivor and those around them. One's character can also shift after a traumatic event—people often describe themselves as becoming "cold," "aggressive," and "cut off" when they were previously a much happier, open person. These traits of the "self" can also, as Brison describes, influence each other and overlap. Brison experienced her PTSD symptoms as not necessarily psychological, but as bodily — her hypervigilance resulted in very real bodily consequences — an increased heart rate and blood pressure, for example. One's psychology can affect one's body, and vice-versa. Even though one can experience a "social murder," where one's body survives but their self is killed, the "new" self and body are still undeniably linked, with one often influencing symptoms in the other. 
If trauma creates two selves - the self "before," and the self "after"- then the traumatic event serves as the link between these two selves, and can provide answers for why the "after" self has formed in the way that it has. If one is to theorize about this second self, the traumatic event is a necessary piece of the puzzle. In providing her own testimony of her experiences before, during, and after her rape and attempted murder, Brison not only provides a stronger theorizing of what it means to "selfannihilate" after trauma, but provides an argument for the existence of the personal narrative within theorizing. Her experiences act as a link — she cannot theorize without them, and she cannot make sense of the experiences and heal from them without theorizing.

Approaching this task from an analytic philosophical framework created "nothing but a list of paradoxes" because the epistemic framework simply did not allow for trauma to exist, even when the existence of it was necessary for the theorizing to take place. Personal narratives from "the real world" are "messy," but "pure thought" is not-it is, rather, "neater... controllable... and comprehensible" (38). Trauma can not be divorced from its personal and emotional nature, and in turn, a field that does not recognize the knowledge inherent in the personal and the emotional is not going to be a field in which a trauma narrative is intelligible. This inability to write her personal experiences under an analytic philosophical framework is not because her colleagues in that space are actively hostile towards rape survivors, nor is it because the space is explicitly exclusive of trauma. The assumptions of analytic philosophy simply leave trauma unintelligible under that framework, silencing Brison's experiences in the process. As Brison recognizes, feminist philosophy “takes women's experiences seriously," and trauma theory "takes survivors' experiences seriously" (28). Certain spaces on the epistemic terrain are always going to produce epistemic injustice by nature of their own epistemic frameworks that 
silence the knowledge of emotions. However, this does not mean that trauma survivors will always meet this type of epistemic injustice. Whether it is by literally moving ourselves to a different physical space, or by shifting the frameworks we use to make sense of our experiences, trauma survivors can find spaces that will allow us to share our stories and have them heard.

\section{The Personal is Political, Philosophical, Powerful}

So, why does it matter that trauma survivors seek out and create spaces on the epistemic terrain that embrace the personal narrative? To put it simply, the personal narrative is crucial not only to trauma recovery, but also to political action. Sharing one's story is a powerful act of survival, but if we are to engage in it, we must, as Bailey describes, "navigate these [epistemic cartographies] creatively."

In Trauma and Recovery: The Aftermath of Violence-From Domestic Abuse to Political Terror, Judith Herman writes of the importance that "reconstructing the story" has for survivors when recovering from a trauma. In fact, the retelling of the story is often the second step in any type of trauma therapy. According to Herman, this reconstruction acts not only as a way for survivors to fully process the trauma, but as a way to "transform the traumatic memory" in a way that makes it possible for them to integrate it as just another part of their "life story." It is absolutely crucial that this process takes place in a space containing listeners that will be able to actually receive the narrative. Herman discusses this "reconstruction" as an act that takes place exclusively in the context of trauma therapy, but more and more often, we are seeing that this is taking place independently from a therapeutic context, leaving trauma survivors far more vulnerable to the possible negative consequences that can come from sharing one's traumatic experiences. In the aftermath of trauma, survivors are in need of an audience that can handle the process of retelling. If the audience is unwilling to recognize truth in the survivor's testimony, or 
if the entire epistemic framework leaves even sympathetic listeners unable to find the testimony intelligible, there are disastrous consequences for the survivor. Since retelling a traumatic experience helps the survivor process by putting into words that which has previously been unspeakable, a failed retelling is an interruption of this act of processing that mimics the original failure to process that created the trauma in the first place. When we seek out and create spaces that foster the retellings of our traumatic experiences, we are investing in our own recovery and survival.

The personal narrative can also function as a powerful political act, especially when the narrative in question is a trauma narrative. We live in a culture that systemically silences the voices of the marginalized, especially with regards to the trauma that these groups suffer at the hands of the systems that oppress them. Refusing to stay silent in the face of this culture is an act of resistance bolder than it gets credit for being. While sharing one's experiences with trauma does not automatically dismantle these systems, vocalizing how one has been harmed by these systems is an important step in the process. Recent movements such as the \#MeToo movement show that when people feel empowered to share their experiences, it can provide the inspiration to make the changes that we need to make in our culture. Of course, just as one needs the right epistemic conditions to heal from trauma through the personal narrative, these same epistemic conditions need to be met for a trauma narrative to meet its political potential. In the case of the \#MeToo movement, part of what made the conditions right for more and more people to share their experiences with sexual assault was the sense of unity that the movement created for people. When people knew that they were not "alone" in sharing their experiences, they felt less disempowered to share them. In the wake of Harvey Weinstein, the general public was also more "ready" for this type of movement. 
There are certain spaces that tend to produce epistemic injustice by the very nature of the space's epistemic framework. These spaces are especially incapable of handling narratives that deal with trauma, since trauma narratives already defy the traits that most people commonly associate with a "credible" story. However, these spaces are not representative of the epistemic cartography as a whole. When we seek out and create spaces that honor the narratives of trauma survivors, we can not only facilitate healing from trauma, and resist epistemic injustice, but we can help to spark political change. 


\section{CHAPTER III: TRAUMA AND MEMORY: FALSE CONSTRUCTIONS, RESURFACED}

\section{TRAUMA, AND THE PARADOXES OF TRAUMA}

In the preface to her memoir Hiroshima in the Morning, Rahna Reiko Rizzuto discusses the relationship between time and memory, and how each affects the "truth" of a story. "Memory," Rizzuto states, "is just how we choose to remember" (11). Because of this, she reminds her readers that she "could tell [them] the story, but it won't be true" (11). According to Rizzuto, time and how we choose to remember warps the concept of objective truth—if memory is a choice we make, no story we tell of the past is going to be the full truth, even if we are not consciously lying. This is especially true when it comes to retellings of traumatic experiences. If memory is a construction, then traumatic memory is a fractured construction. If, as Herman states in Trauma and Recovery, trauma occurs when the brain fails to fully process an event, then it follows that the memory would also be a failed or incomplete construction. This is why some survivors of trauma cannot fully remember the actual details of the event that caused their trauma, but instead remember it in certain colors, sounds, or smells. Some trauma survivors do not even remember the event at all—-the brain will choose certain things to remember, or simply choose to not remember at all. There are many ways in which traumatic memory's very nature puts it at odds with the truth, and further, with credibility. This, however, does not mean that the memories are wholly false—simply incorrectly constructed. Like Brison's, Rizzuto's memoir reveals several important aspects of how trauma is retold. First, Rizzuto's exploration of time and memory sheds light on how no memory is fully "credible" in terms of how we typically measure credibility, and how traumatic memory is compounded in its inherent lack of credibility according to societal standards. Second, Rizzuto's experiences with interviewing hibakusha (Japanese term for survivors of the Hiroshima and Nagasaki bombings, literally translated as 
"explosion-affected people") both before and after the September $11^{\text {th }}$ attacks show the ways in which certain conditions have a way of making trauma resurface in ways that we do not fully expect. Finally, Rizzuto's memoir reveals how easy it is for those in power to gaslight victims of abuse by constructing an entirely new story that gets carved into our cultural memory, making it even more difficult for survivors' testimonies to be heard.

In this chapter, I analyze Rizzuto's experiences with these aspects of how trauma is retold and explore the ways in which they connect to how epistemic injustice is committed against trauma narratives, especially through gaslighting. In doing so, I argue that the nature of trauma and memory puts trauma survivors at an automatic disadvantage for having their experiences being seen as trustworthy, especially when their constructed memories are at odds with what others believe to be true about events that cause mass trauma, like the Hiroshima and Nagasaki bombings. I also explore the ways in which certain conditions can make trauma resurface, with a focus on how one person's retelling can prompt another person's retelling. In revealing the paradoxes inherent in traumatic retellings, and how these paradoxes can lend themselves to epistemic injustice, I build upon my previous work on space and audience to work towards a theory of epistemic trauma.

\section{Trauma and the Construction of Memory}

In Hiroshima in the Morning, Rizzuto writes of her experience with taking a six-month trip to Japan (her first time being away from her family for so long) in order to interview the remaining survivors of the atomic bombing in Hiroshima. Over the course of her time in Japan, Rizzuto experiences a resurfacing of her own traumas — not only is she being constantly reminded of her mother and her worsening dementia, but she experiences further fractures in an already frayed marriage. On top of this, the $9 / 11$ attacks help to drive even more of a wedge into 
her marriage, but help to create a link between her and the hibakusha. Her trip to Japan is an experience in the "undoing of self" that Brison describes in Aftermath—Rizzuto finds herself to not be the same person she was before she went on the trip. This undoing becomes abundantly clear in the final section of the book, in which Rizzuto's husband and their two sons visit her in Japan, and Rizzuto realizes the extent to which she has separated herself from her life as a mother and wife, and how her trip to Japan was just as much a trip to run away from her marriage and motherhood as it was to interview the hibakusha. Through her experiences, Rizzuto ends up making important connections between trauma, memory, and the relational aspects of traumatic retellings.

Rizzuto's complicated experiences with memory make up much of her own narrative throughout the memoir. Her time in Hiroshima is peppered with frustrations over how "the world has forgotten Hiroshima" (50). These frustrations were compounded after 9/11, when many people in the United States - including Rizzuto's own husband - were debating whether or not a counterstrike on the Middle East was justified. As she witnessed the lasting consequences of the U.S.'s first atomic bombs, she could not fathom how quickly others had forgotten just how devastating such an attack really is. This disagreement was yet another wedge into Rizzuto's already fraying marriage, and another reminder of what she was trying to run away from - her own disappointment with her life as a wife and mother. Rizzuto's interactions with her mother serve as constant reminders of what she is desperately trying to forget. Instead of facing the truth of her marriage, she attempted to choose to remember the good memories, which was somewhat doable when she was away (save for the reminders through her and her husband's interactions). However, this attempt completely fell apart as soon as her husband and children joined her in Hiroshima. When she was back with all of them in person, she could not rely on her falsely 
constructed memory — she had to face the whole of her situation, including what she was trying to forget.

If memory is, as Rizzuto states, "how we choose to remember," this statement rings especially true for traumatic memories. When someone experiences a traumatic event, their brain fails to process this event. As Brison describes, it is as if the brain "reacts one second too late" $(\mathrm{xx})$. Because of the inability to initially process the event, the brain falls into a repetition of the event to cope with the failed processing (Herman). A similar process happens with one's memories of the traumatic event. It is common for survivors of trauma to have incomplete memories of the event. Oftentimes, the event is solidified in a way that defies the "true" chronological order of the event, or in a way that allows the survivor to remember only seemingly minute details that are more attached to sensory experiences during the event. In his book Columbine, Dave Cullen describes the ways in which details can easily become mixed up during traumatic events:

We tend to record fragments: gunshots, explosions, trench coats, terror, sirens, screams. Images come back jumbled, but we crave coherence, so we trim them, adjust details, and assemble everything together in a story that makes sense. We record vivid details, like the scraggly ponytail flapping against the dirty blue T-shirt of the boy fleeing just ahead . . a a witness may focus on that swishing hair. Later, she remembers a glimpse of the killer: he was tall and lanky — did he have scraggly hair? It fits together, and she connects it. Soon the killer is wearing the dirty blue T-shirt as well. Moments later, and forever after, she is convinced that's exactly what she saw (205).

These fractured memories of trauma survivors often act as reasons for others to not believe their testimonies. In "Bearing Witness, or the Vicissitudes of Listening," Dori Laub describes an 
instance of an Auschwitz survivor speaking about her experiences to a group of historians. She described "four chimneys" that exploded during the Auschwitz "uprising." The survivor was later criticized for her "inaccurate" testimony—she had misremembered the number of chimneys that exploded at Auschwitz — and the historians decided that because of that one incorrect detail, none of her testimony could be trusted. However, even though it is an "empirical fact" that only one chimney exploded, it would be incorrect to assume that the survivor was intentionally lying about her experience. For whatever, reason, the survivor's brain "recorded" that there were four explosions-for the survivor, that is her chosen memory that becomes her truth.

When Rizzuto explores the relationship between trauma and memory, she not only explores how individuals construct their own memories, but how certain outside factors can affect how one's memory is constructed for them. This is most apparent when Rizzuto describes how her Aunt Molly spoke of her own experiences with traveling to Japan in the aftermath of the atomic bombings. Her aunt spoke of originally thinking that she and the doctors from the United States were there to help the survivors by collecting stillborn babies, but eventually realizing that "they were the enemy," working with the government and "classifying all information so no one could fully understand what the bomb did" (28). The United States government was not there to offer help, but to ensure that they had control of how the event would be constructed in history. If there are no bodies of stillborn babies, there is also no ground to claim that one gave birth to a stillborn baby as a result of the atomic bombings. The testimony of her aunt's experience reveals the ways in which collective memory of an event can be constructed for the benefit of another. This type of outside construction produces memories that are in conflict with one another. Those of us in the U.S. who were told the version of the story constructed by our government have a memory of the atomic bombings that seemingly contradicts the testimony of those who lived 
through the bombings in Japan. If a survivor were to retell a lived experience with the bombings that contradicts what those in America know to be "true" about the bombings, they naturally would not have any credibility in the eyes of an audience that has been taught a highly constructed version of events. What is interesting about this interference by the U.S. government is that they were not necessarily working to force the survivors of the bombings to forget their experience, but that they instead constructed and retold a version of events that would leave survivors with a credibility deficit. This reconstruction was facilitated by the U.S.'s position as a major world power-how could survivors share a testimony against the U.S. government and be taken seriously? The power of a constructed story is even enough to overpower those who know that it is a false construction—even though Rizzuto remembers her aunt describing that she turned to peace activism after realizing the truth behind the work she did in Hiroshima, in one of their later conversations, her aunt went back to describing her time in Japan as the "highlight of her life" (33). On some level, Aunt Molly had gone through the process of realizing what she was doing in Japan was far from the "helping" that they were told they were doing. However, this is an extremely difficult piece of knowledge to live with. The "official" U.S. narrative is, in many ways, the more attractive option. This is where Rizzuto's description of "choosing to remember" comes in. When one experiences a traumatic event, it is sometimes easier to believe the false construction of it than to face what actually happened - the attraction of the false narrative is how some sexual assault survivors will convince themselves to believe that their encounter was consensual, or how survivors of familial abuse will convince themselves to believe that their family is loving and supportive. Believing the false construction is easier than doing the work involved in coping with the truth. When those in power can take advantage of this on a mass scale, the false construction can gain such traction that it is accepted as an 
objective truth, making it impossible for those who wish to push back against the construction to be seen as credible.

This type of deliberate false construction is not limited to major events such as the atomic bombings - it can happen on much smaller scales. A classic tactic used by abusers is to present oneself as an upstanding citizen in every aspect of one's life. If someone's social circle knows of an abuser as a good friend who "wouldn't hurt a fly," then the victim of that person's abuse is at an automatic disadvantage should they choose to speak out about their abuse. This tactic often goes hand-in-hand with an abuser's gaslighting of their victim - making the victim both feel and appear to be "crazy" works against their ability to call out their abuser. If a victim is "crazy," we will have a much harder time believing their testimonies about their abuse, and when we cannot believe, we reify the power of the abuser not only to commit abuse, but to get away with it. In “Allies Behaving Badly: Gaslighting as Epistemic Injustice,” Rachel McKinnon classifies gaslighting as an "instance of testimonial injustice"-this is because instances of gaslighting rely on the same identity prejudices that are at the core of testimonial injustices. McKinnon describes the prejudice present in instances of gaslighting through her example of Victoria, a trans woman who attempts to share an instance of misgendering with her colleague, Susan, who brushes off her experience by insisting that Victoria "must have misheard him," because Susan "had never heard him do it [misgender someone] before" (3). McKinnon points out that the stereotype at the heart of this interaction is that "trans women are overly emotional, perhaps particularly if they're on estrogen-based hormone replacement therapy" (4). As McKinnon states, this perceived "emotionality" of Victoria, and of all trans women, "undermines rationality and perceptual reliability," making this "classic testimonial injustice" (4). Susan's gaslighting produces a counternarrative to Victoria's experiences, leaving paradoxes for Victoria and anyone else who 
hears about the event to have to attempt to make sense of. Victoria is automatically at a disadvantage in winning this battle of the paradox, since her status as a transgender woman leaves her on lower epistemic ground than Susan, a cisgender woman. This is almost never an intentional act —in fact, in McKinnon's example, Susan is someone who thinks of herself as a trans ally. However, it is often the gaslighting from our supposed "allies" that hurts the worst. As McKinnon argues, “one primary function of 'allies' is to provide support ... but if we don't trust our 'allies,' then we lose a critical source of epistemic and moral support." In gaslighting Victoria, Susan not only undermines Victoria's testimony, but allows their colleague's casual transphobia to go unchecked. The result is that Victoria loses her trust in Susan and the sense that she can share an experience with transphobia and have her story believed, and the colleague is allowed to continue to misgender Victoria, along with other trans people he may encounter in the future. When we fall back on an assumption that a speaker must be "crazy" or must have "misheard" another's words, we end up shifting the blame for misbehavior onto the victim, and the effects of this are extremely detrimental to survivors.

This type of gaslighting is often a main factor at play during situations like the Bill Cosby rape scandal — the accusations of over fifty women was incongruent with the collective perception of Bill Cosby, so it was harder for the women's testimonies to receive uptake. Those who have a memory of Cosby as "America's Dad" who could "do no wrong" are not being intentionally deceptive any more than those who have a lived experience of Cosby as a sexual abuser. The person in power-in this case, Cosby—is the one constructing a false memory that becomes one group's version of truth. Defenders of Cosby who clung to his image as "America's Dad" were perpetuating a mischaracterization of Cosby, but they were not always doing so out of active and intentional malice - they were defending the version of Cosby that they experienced 
as truth, and in doing so, they ended up gaslighting Cosby's victims on a mass scale. In a way, Cosby duped his defenders into doing his gaslighting work for him. Because of his status and our own cultural prejudices against women, this was an easy task to accomplish. To his followers, he was the upstanding citizen - their "dad" — and the women he assaulted were "money-hungry whores" who "wanted to make a quick buck," which, according to them, is true of all women. If one's prejudices against women lead one to believe that they are all hysterical, manipulative, and "money hungry," then women are at an automatic disadvantage for their testimonies receiving uptake from anyone, let alone “America's Dad." While many abusers engage in their own gaslighting work, those with higher amounts of power are able to sit back and watch while others do it for them — Cosby could simply plant the seed, and watch as his defenders made it grow.

As we see in Rizzuto's memoir, this kind of triangulation of gaslighting occurred in the aftermath of the atomic bombings as well. When the U.S. government sent over representatives to speak to survivors of the bombings, they were counting on the representatives to not only gaslight the survivors, but to construct a false narrative of the bombings and the aftermath back home in the U.S. In a way, both sides were gaslighted, but American citizens' post-gaslighting construction of the event helped to further gaslight the survivors and discredit their lived experiences. If we apply Fricker's definition of testimonial injustice (an instance in which a hearer's identity prejudice causes a credibility deficit for the speaker) and McKinnon's inclusion of gaslighting as an instance of testimonial injustice to the U.S. government's efforts to control the narrative about the atomic bombings, we can see that many of the same principles were at play. First, an instance of testimonial justice relies on the presence of a hearer's identity prejudice that will prevent them from seeing a speaker's testimony as credible. There were several identity prejudices at play when it came to Americans' perceptions of Japanese people 
during World War II. On top of racial prejudices, Japanese people—even Japanese Americanswere seen as the enemy of American people. Because of their "enemy" status, they were seen as deserving of traumatic situations such as the atomic bombings. In contrast, American people, and by extension, the American government, were seen as trustworthy — they were "in the right." Even before the intentional gaslighting by the U.S. government, survivors of the bombing would be operating on a credibility deficit. The efforts of the U.S. government to control and obscure the narrative of the bombings compounded this credibility deficit—in particular, by collecting stillborn babies, they ensured that even if a survivor tried to come forward with their experience, they would not have the proof necessary to speak out against the U.S. government's narrative. Those who did the work of the government did not even realize that they were causing harm—as Rizzuto's Aunt Molly says, she thought she was helping people. Just like how Susan in McKinnon's example was not intentionally gaslighting Victoria on behalf of James, the U.S. representatives in Japan were not acting out of intentional malice - they were just as duped by the U.S. government. The power of the trust people had in the U.S. government was so strong that even Aunt Molly, who had realized that the work she was doing was the work of gaslighting, eventually regressed back to the idea that her time was "the highlight of her life." Aunt Molly's experience with forgetting the reasons behind her trip to Japan is a complicated mix of her own guilt and desire to forget (as Rizzuto states, "memory is what we choose to remember") and the seductive power of the U.S. government's false construction helped her to run away from this guilt.

\section{Traumatic Retellings}

When Rizzuto first went to Japan to interview the hibakusha, she found that most people were mostly unwilling to share their experiences. Rizzuto comments that when she talks to 
survivors, their answers to her "felt packaged, pre-prepared" (74). She described having to pry for answers, and almost coax people into talking about the bombing at all. When one considers the nature of retelling a traumatic experience, this is not necessarily shocking. Even before one considers the amount of intentional erasure by the U.S. government, a common response to traumatic experiences is to shut down any emotional response to the experience, or just avoid confronting it altogether. In particular, Rizzuto's observations of a survivor sharing his testimony with a group of visitors at the World Friendship Center exemplifies many hallmarks of the numbness that often accompanies a traumatic retelling. Rizzuto mentions that the survivor does not truly talk about the day of the bombing, but rather "recites" a string of events that took place both before and after the bombing. She describes the speaker and his interpreter as both "without expression," and that the story "races past [them], even with the pauses for interpretation, it does not linger." The survivor himself states that in the aftermath of the bombing he and everyone else were numb, and Rizzuto notes that "he is numb now." Rizzuto questions how the survivor "can sit there without crying" and how he can "relive this experience in front of a bunch of gaijin eating shrimp chips.” This is precisely what numbing enables survivors of trauma to do. In fact, in an interview with Cathy Caruth, Robert J. Lifton specifically mentions that Hiroshima survivors used numbing in conjunction with this type of narrative confrontation as a means of healing. Rather than it being a way to "escape" dealing with trauma, the numbing of emotions allows one to share their story and begin to confront what happened to them without the perceived "danger" of reliving the emotional aspect of the traumatic experience. The survivors who use this technique are not "running away" from the emotions as many people often think, but are actually working to manage the emotions so they do not feel as debilitating when memories of the event come up. 
Often, this kind of rehearsed, numb, and expressionless traumatic retelling stems from the discomfort that most people feel with these experiences. For the survivor, bringing up these memories is an extremely difficult process, and for the listener, it can be deeply uncomfortable to truly bear witness to these narratives. This discomfort is seen on the audience's end when they are able to ask the survivor questions- - when each person has the chance to share their questions, they do not address them to the survivor himself, but rather to his translator-Rizzuto notes that it is "as though he [the survivor] was an object." As discussed in the previous chapter, the amount of discomfort involved in bearing witness to a traumatic retelling often causes potential hearers to avoid engaging with the narrative just as much as the speaker might avoid retelling their experience in the first place. And, just as the numbing of emotions acts as a way for trauma survivors to safely engage with their trauma, the act of speaking to the translator instead of the survivor is a way for the audience members to keep themselves "safe" from the emotions involved in bearing witness to trauma. If they can speak to the survivor through a mediator, it becomes easier to handle the retelling because they are neither speaking to him nor receiving the answer from him—everything is secondhand, and therefore, "safer" to take in.

Rizzuto continues to have similar experiences in her conversations with the hibakushano one seems to want to get to "the real story," as Rizzuto calls it, and to her frustration, she feels as though the world has "forgotten" Hiroshima. However, a shift occurs in her interactions with the hibakusha after the attacks on September $11^{\text {th }}$. Her first interview in a post 9/11 world takes place two days after the attacks, with Dr. Fujita, one of the few doctors present during the bombings who is still alive. Rizzuto finds that, in contrast to her previous interviews, Dr. Fujita's responses are vivid, emotional, and detailed — she muses that "for the first time during one of 
[her] interviews, there is no need to keep her [Dr. Fujita] talking or press for details. Either she has an incredible memory, or something has opened up in her today" (151, emphasis mine). This possibility that something "opened up" in Dr. Fujita that caused her to be so forthcoming with her answers is at the core of how this memoir tackles the question of how trauma is retold. When the other survivors' responses were so rehearsed and choppy, what changed for Dr. Fujita to be able to open up to Rizzuto? How did the attacks on 9/11 play a role in this? When Dr. Fujita finishes retelling her experience, she takes a moment to talk to Rizzuto about the attacks, and much to Rizzuto's surprise, she "makes no relative judgment between the two." Rizzuto mentions to Dr. Fujita that "what happened to her ... and Hiroshima was a hundred times worse," but finds that "in Dr. Fujita's eyes, there is a break in the timeline, a union of past, present, and future ... it doesn't lessen her sorrow" (152).

In my previous chapter, I discussed how the sharing of trauma can prompt a retelling because one's retelling can carve out a space to allow for future retellings. What we see in this interaction between Rizzuto and Dr. Fujita is that even without a formal retelling on Rizzuto's part, there is a recognition of a shared tragedy. So, the sharing of a trauma not only opens up a space for future retellings, but creates a link based on shared trauma between people that can help to prompt these retellings. Rizzuto's presence served as a link between the atomic bombings in the past, the 9/11 attacks in the present, and the world's fear for what might happen as a result in the future. Rizzuto's frustrations with her husband's attachment to the jingoism of the post9/11 world rang true for many Hiroshima survivors who knew firsthand what American retaliation looked like, and how quickly the world forgot about the sheer horror of their realities. This could also play a role in survivors' willingness to retell their experiences - when the talk of 
an entire nation is whether or not they will retaliate for the 9/11 attacks, this could naturally cause memories of America's last retaliation to resurface for survivors of the atomic bombings.

Of course, the resurfacing of the hibakushas' traumatic experiences is not the only resurfacing that takes place during Rizzuto's trip to Japan- her own trauma surrounding her mother's worsening dementia is consistently resurfaced throughout the memoir. Rizzuto describes her mother as only experiencing the present, which she describes as potentially "less 'real' than the past" (50). She also describes her mother as "no longer who she once was" (50), mirroring Brison's theorizing of the undone self after a traumatic event. This "new" version of her mother that she is experiencing leaves her mother incomprehensible to her-it is as if she already lost her mother, at least as she knew her. This resurfacing of Rizzuto's own trauma is yet another example of the conditions that can prompt a resurfacing of trauma. Throughout her memoir, Rizzuto describes feeling frustrated with the ways in which the world has seemed to have "forgotten" about the atomic bombings and the lasting pain they caused for the survivors. What is interesting about this frustration is that it is juxtaposed with her mother's dementiarelated forgetting of her own experiences during World War II. Similarly to how the aftermath of 9/11 caused memories of Hiroshima to become resurfaced based on a recognition of shared tragedy, it is possible that Rizzuto's memories of her mother were resurfaced by the recognition that it was not just her mother who had forgotten - it was the rest of the world as well.

Rizzuto's experiences that she outlines in her memoir reveal the role that this type of recognition can play in prompting a traumatic retelling. In many ways, this recognition of shared trauma is what helped the \#MeToo movement gain such traction. Not only did the sharing of such stories help to carve out a space in which others' stories could be made intelligible, but the links created by a recognition of shared trauma helped others to feel more safe in sharing their 
experiences - they knew they were sharing with people who could potentially understand these experiences on a better level. Hearing others' experiences helped to make countless women realize that their voices could also be heard. Of course, the flip side of this phenomenon is that it is yet another feature of trauma retellings that leaves them subject to epistemic injustice. In both the Cosby scandal and the \#MeToo movement, skeptics cited that the sharing of stories seemed to be more of a "trend" that everyone wanted to join in on-instead of recognizing that traumatic retellings by their very nature cause trauma to resurface and therefore prompt more retellings, many people assumed that the sudden influx of disclosures was the result of people "lying" so they could participate in a "trend." This, of course, is based in a stereotype that women are inherently obsessed with all things "trendy" and are constantly seeking attention-if one subscribes to this belief, and that belief is paired with a misunderstanding of how traumatic retellings function, epistemic injustice is sure to follow.

Rizzuto's experiences with the trauma of the hibakusha and her own trauma reveal important facets of how trauma is retold, but they also reveal even more paradoxes that are inherent to trauma narratives: they are emotional by nature, but sometimes unemotional out of necessity. They are deeply personal, but also relational. They are rooted in a survivor's embodied knowledge of an event, but can often exist in contradiction to known facts about an event. The paradoxes of traumatic retellings are at the core of the epistemic violence committed against trauma survivors. In the next chapter, I explore in greater detail the ways in which these paradoxes contribute to epistemic injustice, and the damage this can do to trauma survivors, to the point of even causing additional trauma. 


\section{CHAPTER IV: TOWARDS A THEORY OF EPISTEMIC TRAUMA}

The nature of traumatic retellings often leaves their tellers more vulnerable to epistemic injustice. Because a retelling is often erratic, atemporal, and associated with a number of paradoxes, it is unintelligible in a number of spaces. The danger in this is that in the aftermath of a traumatic event, an epistemic injustice brings its own set of complications for the survivor. Epistemic injustice has the power to reinforce previous trauma, or even "re-traumatize" a survivor, which can have disastrous effects for survivors. According to Lindsay M. Orchowski, Amy S. Untied, and Christine A. Gidycz's study “Social Reactions to Disclosure of Sexual Victimization and Adjustment Among Survivors of Sexual Assault" (2013), the acute responses people have when someone discloses a sexual assault are the top indicators of whether or not that person will develop Post-Traumatic Stress Disorder (PTSD). Orchowski, Untied, and Gidycz found that in cases where the first response in the aftermath of an assault was to control the survivor's actions or decisions, undermine their experience, or accuse them of lying, the survivor of the assault developed a much greater presence of PTSD symptoms. Conversely, in responses where the "hearer" believed the survivor, affirmed their experiences, and allowed them to have control over how they moved forward, little to no PTSD symptoms were developed. So, epistemic injustice not only compounds the trauma one has already experienced, but can prevent someone from healing properly from this trauma. When someone can not speak their trauma and be heard, they are denied the very first step in recovery as articulated by Herman, and are therefore denied recovery altogether until they find a space and audience that can hear their experience as truthful. However, when one's first retelling results in epistemic injustice, will they be willing or able to seek out this other space, or will they be discouraged from doing so? 
In this chapter, I argue that when one experiences an epistemic injustice in the aftermath of a trauma, what occurs is not simply an additional psychological harm, but a second-order trauma. I refer to this type of trauma as epistemic trauma, or, a trauma to one's ability to know their experience, and to make a claim based on this experience. While epistemic trauma can certainly overlap with psychological trauma, I argue that the two are still distinct forms of trauma that hold their own sets of consequences for survivors. To work towards this theory of epistemic trauma, I first distinguish the differences between all three types of trauma. I then provide examples of what epistemic trauma might look like applied to real-life situations, obtained either from events featured in world news or from conversations I have had with others. In exploring these examples, I point out how epistemic trauma can function in ways that are serious and ways that are seemingly mundane. I then revisit the depictions of trauma I have discussed in my previous two chapters - namely the notions of the annihilated self and the paradoxes of traumatic retellings - to explore how each works in the context of an epistemic trauma. Finally, I work towards what I see as the implications of epistemic trauma, and what we might do to help prevent and heal from this type of trauma.

\section{Physical Trauma, Psychological Trauma, and Epistemic Trauma}

Physical, psychological, and epistemic traumas often overlap in both occurrence and symptoms, but all three have distinct features from one another. Physical trauma refers to the literal physical harm done to one's body. Physical trauma is present in traumatic events including but not limited to sexual assault, physical abuse, some combat situations, and life-threatening accidents. Physical trauma can range from life-threatening injuries, some more permanent, to more minor injuries. However, while the physical trauma can often heal, it is more often than not accompanied by psychological trauma. 
According to Laurie Anne Pearlman and Karen W. Saakvitne in Trauma and the Therapist, psychological trauma (sometimes referred to as emotional trauma) occurs when "the individual experiences (subjectively) a threat to life, bodily integrity, and sanity" and subsequently, "the individual's ability to integrate his/her emotional experience is overwhelmed" (60). While physical trauma can and often does result in psychological trauma, it does not need to exist for one to experience psychological trauma. Things like emotional abuse, witnessing a violent act, growing up in a home with an alcoholic or a drug addict, or experiencing a natural disaster can all cause psychological trauma, even with the absence of a physical trauma. Psychological trauma is often associated with the more long-term effects of a traumatic event, such as the development of PTSD. This can have potentially deadly consequences, since those with PTSD have a higher rate of suicide than those without (Hudenko, Homaifar, and Wortzel).

Epistemic trauma is different than that of physical or psychological trauma in that, on the surface level, it seems not as serious. However, its seemingly mundane nature makes it even more insidious. An epistemic trauma is a type of trauma that I argue happens after repeated or severe epistemic injustice. The repeated silencing of epistemic injustice is a unique type of violence that, in turn, causes a unique type of traumatic response. Being met with epistemic resistance at every turn ends up harming one's ability to see themselves as a "knower," and when one cannot see themselves as a "knower," they are less likely to enter further situations in which they will have to make a truth claim. If they are epistemically traumatized into not being able to see themselves as a knower, the mere idea of making a truth claim seems impossible. Epistemic trauma can take form in two different ways, or as a first-order and second-order epistemic trauma. First-order epistemic trauma refers to when the repeated silencing of epistemic injustice traumatizes one as a knower. This type of epistemic trauma does not need to be paired with a 
physical or psychological trauma - it can develop in otherwise non-traumatic contexts. Secondorder epistemic trauma refers to when an epistemic injustice in the aftermath of a traumatic event causes a second-order trauma. The consequences of epistemic trauma for a survivor can be serious, especially when one experiences an epistemic trauma in the context of a physical or psychological trauma. Again, as Orchowski, Untied, and Gidycz state, an epistemic injustice in the acute aftermath of a traumatic experience raises one's likelihood of developing PTSD, which brings on an entirely new set of risks, including a higher percentage of suicidal ideation and attempts. In addition to the harmful consequences for the survivor, there is the potential for a social harm. When a person is epistemically traumatized, they are less likely to make truth claims, whether pertaining to trauma or not. In “Tracking Epistemic Violence, Tracking Practices of Silencing," Dotson states that when a listener cannot "meet a speaker halfway," the communicative exchange has failed and the speaker has been silenced. Dotson articulates this as a specific form of violence that works to "disappear non-Western knowledges." However, this is not the only harm in silencing - the very silencing that traumatizes speakers robs listeners of experiencing the knowledge of the speaker's experiences. While this seems like a miniscule harm in comparison to the harm and trauma for the speaker, it can have large-scale social repercussions. There are countless survivors of sexual assault who, because they experienced an epistemic trauma in the aftermath of their assault, are unwilling to ever share their experience again because of the failed first attempt, and countless activists who no longer wish to share their own experiences with identity-based oppression because of the continuous epistemic resistance they face. While the speakers in these situations suffer the initial harms, there are consequences for all of us when it comes to epistemic trauma. 


\section{An Applied Theory of Epistemic Trauma}

To further work through how epistemic trauma functions, I will explore three different real-life (either from events covered in world news, or from personal conversations) scenarios where I believe an epistemic trauma is at play - the first two scenarios showcasing a secondorder epistemic trauma, and the final scenario showcasing a first-order epistemic trauma. Each scenario involves a different timeline and context of epistemic trauma, to showcase the myriad of situations in which an epistemic trauma can occur. After describing each scenario, I will walk through where I believe an epistemic trauma occurred and how it functioned in each scenario.

\section{Scenario One}

Rehtaeh Parsons was a Canadian teen who, in 2013, survived a brutal gang rape committed against her by four schoolmates. After reporting the assault, Parsons faced extreme bullying and harassment from schoolmates who called her a "liar" and a "slut," and stated she was simply "seeking attention." On top of this, the police investigating her case had declared it to be a "hesaid-she-said" situation, and decided that the photos and videos circulated of Parsons' assault were "non-criminal" (the RCMP would reopen the case in the aftermath of Parsons' suicide). Parsons attempted suicide by hanging herself, and three days later, was taken off life support.

\section{Scenario Two}

A Latina woman who actively participates in anti-racist activism often shares her own testimonies of experiences with racial injustice - some traumatic, some not. Whenever she shares these testimonies, she is met with epistemic injustice from her white friends who either downplay her experiences, gaslight her in the process, or flat-out refuse to believe her. After so many repeated instances of silencing, she begins to doubt her own experiences, worried that she is "overreacting," and eventually no longer feels comfortable sharing her experiences with 
racism. Finding herself in situations where she might be expected to share her personal experiences now makes her anxious, as it reminds her of the failed retellings she constantly experienced at the hands of her friends. After a class session where a professor asked everyone in the classroom to share a personal experience where they had to confront racial issues, the woman's fear that her testimony would face epistemic injustice made her so anxious that she needed to leave the room.

\section{Scenario Three}

A woman boards a plane and sits down in her seat next to a window. A few minutes later, a man boards and claims that the window seat is actually his. The woman had been absolutely sure that she was assigned the window seat, but also thought that she often forgot details such as plane seats and assumed that the man claiming the seat was his must have been right, and that she must have been wrong. The woman did not even think to double-check her boarding pass-since she automatically assumed that she was the one who had sat in the wrong seat, there was no point in doing so. Some time after the plane ride, the woman realizes that the seat was actually hers, and that the man simply assumed that if he made her doubt this fact, he could get her to switch seats with him. Her own lack of epistemic confidence in the situation left her feeling as though she could not stand her ground.

The instance of epistemic trauma is perhaps most apparent in scenario one-Parsons had clearly suffered both a physical and psychological trauma through her gang rape, and when she tried to seek some sort of justice, she was faced with extreme backlash in the form of epistemic injustice. To her classmates, she was a "liar" and a "slut," and to the police, her gang rape was merely a "he-said-she-said situation." Parsons suffered a dual trauma — the trauma of her rape and the subsequent epistemic trauma at the hands of her peers. The physical and psychological 
trauma of the rape itself already worked to shatter Parsons' sense of self in relation to the world around her, and on top of this, her ability to at least share her experience and have it accepted as truthful was taken away from her peers and from law enforcement. She had no way to proceed with pursuing justice because others could not even believe that she was the victim of a crime in the first place. It is, of course, impossible to determine which trauma was the driving force behind her suicide, especially since it was likely the combination of all three that resulted in her suicidal ideation. However, when examining the events leading up to her death, one can certainly see how the epistemic trauma present in Parsons' scenario played a part in her untimely death.

The second scenario showcases not only an example of a longer process of epistemic traumatization, but some of the potential social and individual harms when someone suffers an epistemic trauma. As shown in Chapter Two, personal narratives have a lot of power, especially in activist circles, where testimonies of oppression are often the driving force behind action. If epistemically traumatized people no longer feel as though they are able to share these experiences, what are the implications for potential activism? This woman's story also showcases the potential for epistemic trauma to develop over time as opposed to after a single event. The consistent epistemic injustice and silencing she faced when attempting to share her testimonies eventually traumatized her. An important distinction here is that someone who no longer wishes to share their experiences after repeated epistemic injustice is not always automatically epistemically traumatized. However, this woman's scenario involved full-on anxiety when in situations where she might be expected to share her own experiences. Her not sharing her testimonies was not the result of a conscious decision to stop, but out of a deep anxiety that prevented her from feeling comfortable in trusting others with these testimonies; if people she had shared with in the past would constantly diminish her experiences, surely others 
would as well. This scenario unveils potential symptoms of epistemic trauma that mirror symptoms of the other forms of trauma — avoidance of situations or spaces that remind the survivor of the trauma, diminished sense of trust in the world around her, and feelings of anxiety when reminded of the trauma. Finally, in scenario two, we see how the act of silencing is in and of itself an act of violence - the harms caused by her friends' practices of silencing are what led to her epistemic trauma.

In scenario three, we see what is a less severe example of a person who has been epistemically traumatized. While the event described is not the one that caused an epistemic trauma, it is an example of how one who is epistemically traumatized might move through the world in the aftermath of such a trauma. If epistemic trauma is a trauma to one's ability to know and make a claim based on this knowledge, then it follows that an epistemically traumatized person will move through the world with a diminished sense of epistemic confidence. If we assume that the woman in the scenario had at one point suffered an epistemic trauma, we can see how she became more susceptible to epistemic challenges in the aftermath. When the man boarded the plane and stated that she was sitting in his seat, she was confused, but then assumed that she "must" have been wrong because of her perception of herself as "forgetful," and she felt as though she did not have an epistemic ground to stand on when it came to challenging the man. This is of course not as serious a consequence of epistemic trauma as Parsons' suicide, but an inability to assert oneself in situations like this can alter the way a person moves through the world, even in scenarios as inconsequential as which plane seat they sit in. In this case, the woman's lack of epistemic confidence made her give in to the man's challenge, sacrificing her own comfort based on a claim someone else made. If someone loses their sense of themselves as a knower, and therefore cannot assert their own knowledge of their experiences, could this 
potentially result in more sinister manipulations by those who are seen as holding higher epistemic ground?

\section{The Annihilated Self of Epistemic Trauma}

In Chapter Two, I explored Susan Brison's concept of "selfannihilation" in the aftermath of a traumatic event. Brison describes this as the phenomenon of neither "being oneself in relation to others" nor "being oneself in relation to oneself" (40). In working through her own experience with selfannihilation, Brison showcases the ways in which a trauma can alter one's "bodily continuity . . . continuity of memory, character traits, or other psychological characteristics that makes someone the same person over time" (40). As Brison states, one can die during a traumatic event, but live to tell the tale. To further explore how epistemic trauma functions, I want to theorize the ways in which epistemic trauma can cause this selfannihilation that Brison describes. While I believe that epistemic trauma selfannihilates in a manner that is ultimately distinct from physical or psychological trauma, I also believe there are a number of similarities between how these various forms of trauma can selfannihilate. I see epistemic trauma as not necessarily disruptive of bodily continuity, but as disruptive of continuity of memory and character traits in order to "kill" the version of oneself that existed prior to a trauma.

In looking at the previous scenarios, one can see the most distinct "before" and "after" in scenario two. The woman in this scenario once frequently shared testimonies of her own oppression as an act of resistance. After repeated epistemic injustice that developed into an epistemic trauma, she was not only unwilling to share these experiences with others, but severely anxious by the idea. She also experienced a high amount of self-doubt—she would feel as though she was experiencing her own life "incorrectly" or "reading into situations in the wrong way." The epistemically traumatized self is clearly not a continuation of the pre-traumatized self who 
found power and knowledge in the sharing of her experiences. If we are to see this former willingness as a trait of her pre-traumatized self, then that is a part of herself that "died" as a result of epistemic trauma. She survived the trauma in the literal sense, but the pre-traumatized self can not be said to remain in existence if these facets of the self are no longer present.

The case of Rehtaeh Parsons showcases what is possibly the most extreme selfannihilation of the three scenarios. The epistemic injustice and bullying that Parsons faced in the aftermath of her assault would be enough to make anyone feel as though they are no longer themselves in relation to others around them, and for Parsons, this disconnect led to a literal selfannihilation - the physical trauma and subsequent epistemic trauma created such an extreme "death" of the self that it translated into Parsons bringing about her own literal death.

In scenario three, while we do not necessarily see the "before" and "after" versions of the woman who gave up her plane seat, we can see how epistemic trauma can disrupt one's sense of self, especially in relation to others. Since we do not have a solid idea of what this particular woman's pre-traumatized self was, we can not say for certain that her self has been fully annihilated, but we can see that there is a disorientation of the self. The woman was at first confident that she was in the right seat—after all, she had no reason to believe otherwise. However, as soon as the man challenged her, we see where this sense of self gets muddied. While the woman had been sure she was in the right seat, she suddenly doubted herself, doubted whether she had read her ticket correctly, and assumed that because she sees herself as "forgetful," she must have made a mistake, and that the man was surely correct. Scenarios like this one often display the potential symptoms of epistemic trauma as caused by repeated gaslighting. As Rachel McKinnon states, the goal of gaslighting is to make the victim doubt their own experience, as if they are too "crazy" to see their experiences as what they are, leaving them 
with no epistemic ground to stand on. It follows that the trauma one experiences after repeated gaslighting is an epistemic trauma. The logic of gaslighting can be seen in the woman's thought process - at first she feels as though she is in the right, but then she remembers that she is naturally "forgetful," and feels as though this renders her unable to make a claim. The "self" she inhabits is that of her post-gaslighting self.

\section{The Paradoxes of Epistemic Trauma}

As discussed in Chapter Three, Rahna Reiko Rizzuto's memoir Hiroshima in the Morning reveals the paradoxes inherent in traumatic retellings. A retelling is a deeply personal experience, and yet its success relies on the relationality of the speaker to the audience. It is a retelling of an emotional experience that sometimes relies on unemotionality to even be told. It can even be an expression of embodied knowledge that is at odds with empirical facts about an event. These paradoxes contribute heavily to epistemic injustice in the aftermath of a trauma, making them a potential catalyst for epistemic trauma to compound the trauma already experienced by the person attempting to retell their experience. The traumatic paradox that I see as most linked to epistemic trauma is that of the tension between one's embodied knowledge and what is an empirical fact. In the case of the Holocaust survivor who incorrectly remembered the number of chimneys that exploded of Auschwitz, there was a clear disconnect between what the survivor believed to be true and what was known by others to be true. The main criticism of her testimony was that if she was actually there, why would she get a detail like that wrong? Of course, the survivor was not lying about being in Auschwitz, but had simply remembered the wrong number of chimneys exploding. Her factual error was not out of malice, but out of a simple falsely constructed memory. This scenario alone shows the fickle nature of memory-as Rizzuto states, it is simply "how we choose to remember." However, if memory is inherently 
unreliable, how can we establish the epistemic weight of one's experience? Furthermore, how can we reconcile potentially misremembered details with what we know to be true without harming the person sharing their experiences?

When attempting to work through this paradox, the solution is not simply to believe every testimony we encounter-there will always be those who deliberately share a false testimony with malicious intent, and to believe every testimony without consideration as to what might be behind it will not solve the problems of epistemic injustice and epistemic trauma. A potential solution lies in a more careful consideration of what might be at play when we choose to either believe or not believe a person's testimony, and whether our belief or non-belief is based on the person's identity. We can unpack this potential solution in all three scenarios from earlier, but perhaps most interestingly in scenario three, where identity prejudice potentially resulted in both a credibility deficit and a credibility excess. The woman who was told she was in the wrong seat was told this by a man-even before the woman's own epistemic trauma made her less confident in standing her ground about being in the correct seat, the identities at play made this an uneven exchange in terms of identity and power. In situations like this, the question is just as much what gave the man credibility as it is what took away the woman's credibility. The uneven identity power present in the exchange facilitated the disorientation of the woman's sense of self.

\section{Further Implications of a Theory of Epistemic Trauma}

If we are to work towards a theory of epistemic trauma, we must consider why this is an important theoretical tool to trauma theory, rhetorical theory, and feminist philosophy. If we are to accept epistemic trauma as a form of trauma, what are the possibilities for further studies? One important consideration for rhetorical theory is a complication of what it means to be a credible 
speaker. When traumatic retellings defy our conceptions of what we consider to be a credible narrative, what do we need to change about these conceptions in order to make room for these types of narratives? When the very nature of one's trauma renders them unable to see themselves as worthy of making a claim, how can they participate in rhetorical exchanges? If trauma is arhetorical, how do we complicate our notions of what holds as a rhetorical claim in order to allow for more complicated narratives to exist? The existence of epistemic trauma also provides more possibilities for studying trauma theory—if epistemic trauma has the power to compound one's trauma or even turn an otherwise non-traumatic situation into a form of trauma that carries similar symptoms and consequences as physical or psychological trauma, what do we need to reconsider about the nature of trauma and how it can take shape? Finally, what new work can be done in feminist philosophy on the phenomenon of epistemic injustice if we accept that one of the harms it is capable of is a legitimate traumatization of its victims? What are the potential solutions for epistemic injustice, and further, epistemic trauma when simply believing everyone's testimony cannot be the solution? In my next chapter, I explore potential future areas of study pertaining to epistemic trauma, and how a theory of epistemic trauma becomes even more exigent in our current political landscape. 


\section{CHAPTER V: THE EXIGENCIES OF EPISTEMIC TRAUMA}

It is hard to go a single day without finding new scenarios in which a theory of epistemic trauma becomes useful. In a cultural and political climate where mass traumas seem to happen continuously, and the denial of this trauma is louder than ever, how can the studies of trauma, epistemic injustice, and epistemic trauma help us make sense of it all? Furthermore, how might the healing from our own epistemic traumas, whether mild or severe, help us stand our ground against the constant erasure of trauma narratives in our current political landscape? A theory of epistemic trauma has the potential to help us work through the complicated epistemic terrains with regards to the trauma we now bear secondhand witness to nearly every day. There are a number of contexts where this theory could be applied in illuminating ways, from the \#MeToo and \#NeverAgain movements to instances of generational trauma. If we are able to learn more about these areas, we can become more careful listeners and speakers - those who do not cause epistemic trauma nor are susceptible to it.

Epistemic injustice seems to run rampant under our current political landscape. With a leader who actively encourages the identity prejudice at the root of epistemic injustice, more and more people are finding their experiences to be shut down or erased. In times like these, it is more important than ever to make sure that testimonies of oppression do not fall on deaf ears, but how do we accomplish this when the natures of trauma, identity, memory, and knowledge complicate what we are able to see as credible? This is where both an increased knowledge of the "non-rhetoric of trauma" and a challenge to notions of credibility become useful. When more people are knowledgeable about how trauma often renders narratives arhetorical and noncredible, this naturally opens up more potential spaces for survivors of trauma to share their 
experiences. However, there is a need for a simultaneous challenging of what we deem credible, and why that is so.

This is one of the main areas I would want to explore further in development of a theory of epistemic trauma. If we were to engage in a closer analysis of what we see as a hallmark of being a "credible speaker," might we find that these hallmarks are rooted in whiteness, malebodiedness, able-bodiedness, or upper class status? Since we already know that identity prejudices in all of these areas lead to epistemic injustice, it would follow that perhaps our entire notion of credibility is based on systems of oppression. For example, perhaps someone, in a rhetorical exchange with an autistic person, assumes that the autistic person is telling a lie because they are fidgety and are not making eye contact. This credibility judgment has seemingly nothing to do with an identity prejudice - after all, it was based on the actions of the individual and not necessarily their neurodivergent identity. However, not being able to "sit still" and maintain eye contact are extremely common symptoms of Autism - the individual is not staring off into the distance and fidgeting because they are nervous about lying, but because their autism makes it difficult for them to do otherwise. The seemingly "fair" credibility measure of eye-contact and nervous behavior can only apply to those for whom eye-contact is a possibility in the first place. How can we change our notions of credibility to make room for those who simply cannot meet our standards, even when they are being completely truthful? If the listener makes a faulty credibility judgment based on these seemingly fair criteria, are they as culpable as one who makes a faulty credibility judgment based on an active identity prejudice?

Another area I would love to apply a theory of epistemic injustice to is the study of generational trauma. Many marginalized groups inherit symptoms of psychological trauma from a centuries-long heritage of oppression. These marginalized groups also carry less credibility as a 
result of the identity prejudices many people have against them. If one can inherit symptoms of psychological trauma, might one be able to inherit symptoms of epistemic trauma? Would this inheritance be based in biology, passed down through cautionary tales told to younger relatives or both? If both, would a biological inheritance of epistemic trauma be detectable in medical procedures like brain scans? When one both inherits epistemic trauma and is more susceptible to it because of the identity prejudice against them, what kind of feedback loop is created with regards to traumatization?

Finally, I would want my future studies in epistemic injustice and epistemic trauma to explore potential solutions. As discussed in previous chapters, no solution is ever going to be able to apply to all cases. Nothing will completely eradicate the problem of epistemic injustice, but we can work to minimize it through educating ourselves and others on issues of trauma and epistemic injustice, and we can challenge ourselves to interrogate our own prejudices and how they affect what narratives we give uptake to. While this alone does not completely solve the problem, it helps to get us on a more even epistemic terrain. An even more exigent solution would be to the issue of epistemic trauma - how can we help to rebuild one's sense that they have an accurate knowledge of their own experiences and can make truth claims based on this knowledge? Would existing trauma therapy be able to help those who deal with epistemic trauma heal, or would new therapies need to be developed? How could rhetorical theorists help with the development of these new theories and help those who are epistemically traumatized regain both epistemic and rhetorical confidence in themselves?

The stories we need to hear the most are often the stories that are the most buried. Whether this is the result of malicious erasure such as the tactics employed by our current administration or of a self-silencing stemming from epistemic trauma, the narratives that are 
capable of producing the most change are being silenced. While there is no universal solution to this problem, working further towards a theory of epistemic trauma can help us all to become more cognizant of our own roles in these systems - how can we avoid contributing to another's epistemic trauma? How can we heal from our own epistemic trauma? For many people, this might be work that needs to be done simultaneously — trauma often breeds more trauma, and those who have been epistemically traumatized might be at an increased risk of epistemically traumatizing others. In these cases, making progress towards one end might help with the other-if one begins to recognize and heal from their own epistemic trauma, they can become more cognizant of the ways in which they have been complicit in another's epistemic trauma, and work to change their actions in the future to avoid this harm to others. Further studies in epistemic trauma need to work towards answers to these questions if we are to continue to find power and knowledge in our own experiences. If, as Judith Herman states, "recovery begins when truth is recognized," an understanding of the obstacles to recognizing truth will facilitate this collective recovery from the silence that continues to traumatize us. 


\section{WORKS CITED}

Alcoff, Linda Martin. "Epistemic Identities.” Episteme, vol. 7, no. 2, June 2010, pp. 128-37.

—_. “On Judging Epistemic Credibility: Is Social Identity Relevant?” Philosophic Exchange, vol. 29, no. 1, 1999, pp. 1-22.

Bailey, Alison. “The Unlevel Knowing Field: An Engagement with Dotson's Third-Order Epistemic Oppression.” Social Epistemology Review and Reply Collective 3, no. 10 (2014): 62-68.

Brison, Susan J. Aftermath: Violence and the Remaking of a Self. Princeton Univ. Press, 2003. Cullen, Dave. Columbine. Hachette Book Group, 2009.

Dotson, Kristie. "Conceptualizing Epistemic Oppression." Social Epistemology 28.2 (2014): 115-38. Web. 3 May 2017.

Dotson, Kristie. “Tracking Epistemic Violence, Tracking Practices of Silencing.” Hypatia 26.2 (2011): 236-257. Web. 15 April 2017.

Fahs, Breanne. "Naming Sexual Trauma.” Critical Trauma Studies, 2016, pp. 61-77.

Fricker, Miranda. Epistemic Injustice: Power and the Ethics of Knowing. Oxford UP, 2011. Print.

Gilmore, Leigh. "Limit-Cases: Trauma, Self-Representation, and the Jurisdictions of Identity." Autobiography Vol. 24 No. 1, 2001.

Godbee, Beth. "Writing Up: How Assertions of Epistemic Rights Encounter Epistemic Injustice.” College English, vol. 79, no. 6, July 2017, pp. 593-618.

Herman, Judith. Trauma and Recovery: The Aftermath of Violence-From Domestic Abuse to Political Terror. Basic Books, 1992. Print. 
Laub, Dori. "Bearing Witness or the Vicissitudes of Listening." Testimony: Crises of Witnessing in Literature, Psychoanalysis, and History. 1992.

Lorde, Audre. "The Transformation of Silence into Language and Action." Sister Outsider. Ten Speed Press, 1984.

Menchú, Rigoberta. I, Rigoberta Menchú: An Indian Woman in Guatemala. 1983. Ed. Elisabeth Burgos-Debray. Trans. Ann Wright. London: Verso, 1984.

Orchowski, Lindsay M., Amy S. Untied, and Christine A. Gidycz. "Social Reactions to Disclosure of Sexual Victimization and Adjustment Among Survivors of Sexual Assault."Journal of Interpersonal Violence 28.10 (2013): 2005-2023. Web. 16 Apr. 2017. "PTSD: National Center for PTSD." The Relationship Between PTSD and Suicide - PTSD: National Center for PTSD. N.p., 12 Sept. 2013. Web. 1 May 2017.

Pearlman, Laurie Anne, and Karen W. Saakvitne. Trauma and the Therapist. New York: Norton, 1995.

Rizutto, Rahna R. Hiroshima in the Morning. The Feminist Press at CUNY, 2010.

Solnit, Rebecca. “A Short History of Silence.” The Mother of All Questions. Haymarket Books, 2017.

Spivak, Gayatri Chakravorty. "Can the Subaltern Speak?" Marxism and the Interpretation of Culture, edited by Cary Nelson and Lawrence Grossberg, U of Illinois P, 1998, pp. 271-313.

Vest, Jennifer Lisa. “What Doesn’t Kill You: Existential Luck, Postracial Racism, and The Subtle and Not So Subtle Ways the Academy Keeps Women of Color Out." Seattle Journal for Social Justice 12.2 (2013): 471-518. Web. 17 April 2017. 